\title{
Nickel Oxide Particles Catalyze Photochemical Hydrogen Evolution from Water-Nanoscaling Promotes P-Type Character and Minority Carrier Extraction
}

Benjamin A. Nail, ${ }^{\dagger}$ Jorie M. Fields, ${ }^{\dagger}$ Jing Zhao, ${ }^{\dagger}$ Jiarui Wang, ${ }^{\dagger}$ Matthew J. Greaney, ${ }^{\ddagger}$ Richard L. Brutchey, ${ }^{\ddagger}$ and Frank E. Osterloh*,t

${ }^{\dagger}$ Department of Chemistry, University of California Davis, One Shields Avenue, Davis, California 95616, United States and ${ }^{\ddagger}$ Department of Chemistry, University of Southern California, Los Angeles, California 90089, United States

\begin{abstract}
Nickel(II) oxide (NiO) is an important wide gap p-type semiconductor used as a hole transport material for dye sensitized solar cells and as a water oxidation electrocatalyst. Here we demonstrate that nanocrystals of the material have increased p-type character and improved photocatalytic activity for hydrogen evolution from water in the presence of methanol as sacrificial electron donor. NiO nanocrystals were synthesized by hydrolysis of $\mathrm{Ni}(\mathrm{II})$ nitrate under hydrothermal conditions followed by calcination
\end{abstract}


in air. The crystals have the rock salt structure type and adopt a plate-like morphology (50-90 nm $\times 10-15 \mathrm{~nm}$ ). Diffuse reflectance absorbance spectra indicate a band gap of $3.45 \mathrm{eV}$, similar to bulk Ni0. Photoelectrochemical measurements were performed at neutral pH with methylviologen as electron acceptor, revealing photo-onset potentials (Fermi energies) of 0.2 and $0.05 \mathrm{eV}$ (NHE) for nanoscale and bulk NiO, respectively. Nano-NiO and NiO-Pt composites obtained by photodepositon of $\mathrm{H}_{2} \mathrm{PtCl}_{6}$ catalyze hydrogen evolution from aqueous methanol at rates of 0.8 and $4.5 \mu \mathrm{mol} \mathrm{H}_{2} \mathrm{~h}^{-1}$, respectively, compared to 0.5 and $2.1 \mu \mathrm{mol} \mathrm{H}_{2} \mathrm{~h}^{-1}$ for bulk-NiO and NiO-Pt (20 mg of catalyst, $300 \mathrm{~W}$ Xe lamp). Surface photovoltage spectroscopy of NiO and NiO-Pt films on Au substrates indicate a metal Pt-NiO junction with $30 \mathrm{mV}$ photovoltage that promotes carrier separation. The increased photocatalytic and photoelectrochemical performance of nano-NiO is due to improved minority carrier extraction and increased p-type character, as deduced from Mott-Schottky plots, optical absorbance, and X-ray photoelectron spectroscopy data.

KEYWORDS: photocatalysis · p-type metal oxide $\cdot$ nanoscale junction $\cdot$ surface photovoltage spectroscopy $\cdot$ photocorrosion

P hotoelectrochemical and photocatalytic water splitting have attracted significant attention as methods for generating carbon free fuels from solar energy. ${ }^{1-3}$ Many photocatalysts have been reported to evolve hydrogen from water in the presence of a sacrificial reagent, but stable visible-light responsive photocatalysts for overall water splitting are still very rare. ${ }^{4-6}$ In tandem or z-scheme photocatalysts, water splitting is achieved by the combined photoaction of photocathode and photoanode materials that are connected in series. ${ }^{7-10}$ However, visible light responsive p-type metal oxide photocatalysts and photoelectrodes are still uncommon. ${ }^{11-17}$ In terms of its structure and composition, nickel oxide $(\mathrm{NiO})$ is one of the simplest p-type metal oxides. ${ }^{18}$ Its wide band gap precludes it from visible light absorption, but it is a popular hole transport material in dye sensitized solar cells, ${ }^{19-21}$ and in thin film photovoltaics. ${ }^{22}$ It also has been used as a cocatalyst in water splitting photocatalysts. ${ }^{6,23-27}$ Sometimes the function of $\mathrm{NiO}$ is not clear; ${ }^{28}$ it has been interpreted as a proton-reduction electrocatalyst, ${ }^{29-32}$ as a water oxidation electrocatalyst, $^{33,34}$ or as a photocathode. ${ }^{35,36}$
* Address correspondence to fosterloh@ucdavis.edu.

Received for review January 20, 2015 and accepted April 14, 2015.

Published online April 14, 2015 10.1021/acsnano.5b00435

() 2015 American Chemical Society 
Indeed, under UV illumination, $\mathrm{NiO}$ films perform as photocathodes for hydrogen evolution from water, in the presence of a mild cathodic bias. ${ }^{17,37}$ Even though suspended $\mathrm{NiO}$ particles are photocatalytic for methylene blue and rhodamine $\mathrm{B}$ degradation, ${ }^{36,38,39}$ photocatalytic hydrogen evolution has not yet been demonstrated with suspended $\mathrm{NiO}$ particles. In order to test such a function we have conducted here a systematic study on the photocatalytic properties of bulk and nanoscale $\mathrm{NiO}$ particles. We find that under UV illumination, $\mathrm{NiO}$ particles are photocatalytic for hydrogen evolution from aqueous methanol solution, especially after the addition of a Pt cocatalyst. The activity is enhanced in $\mathrm{NiO}$ nanocrystals because of improved minority carrier collection and enhanced p-type character. This follows from photoelectrochemical and photovoltage measurements on thin films of the material. Overall, these results establish nanoscaling as a way to modify the carrier concentration in $\mathrm{NiO}$ and they provide the first demonstration of $\mathrm{NiO}$ as an UV-active photocatalyst for hydrogen evolution from water, in the presence of methanol as an electron source. The analysis also sheds new light on photochemical charge separation at nanoscale interfaces, as relevant to excitonic solar energy conversion devices.

\section{RESULTS AND DISCUSSION}

$\mathrm{NiO}$ nanoparticles for this study were synthesized by calcination of nickel hydroxide particles as described earlier by Zhang et al. ${ }^{40}$ According to XRD, $\mathrm{NiO}$ is phase pure and crystallizes in the cubic $\mathrm{NaCl}$ structure type (Figure 1). On the basis of the peak broadening the nanocrystal thickness dimension can be calculated as $6.7 \pm 0.7 \mathrm{~nm}$ using the Scherrer equation. According to TEM, bulk NiO particles (Figure $2 \mathrm{E}$ ) are $0.5-1.0 \mu \mathrm{m}$ and show an irregular morphology. The synthesized $\mathrm{NiO}$ nanocrystals, on the other hand, exist as thin plates with diameters ranging from 50 to $90 \mathrm{~nm}$ and thicknesses of 10-15 nm, about twice the diameter obtained from $\mathrm{X}$-ray diffraction. This suggests that the $\mathrm{NiO}$ nanocrystals are not single crystals, despite the wellordered crystal planes observed in HRTEM. The optical properties of $\mathrm{NiO}$ depend strongly on the crystal size. While bulk-NiO powder is green, the nanocrystals appear black (Figure 3). Diffuse reflectance spectra are shown in Figure 3. The spectrum for bulk-NiO is characterized by several $\mathrm{d}-\mathrm{d}$ transitions of the $\mathrm{Ni}^{2+}$ ion in an octahedral $\mathrm{O}$ environment. ${ }^{41,42}$ The corresponding bands at $1.75 \mathrm{eV}$ and at $2.75-2.95 \mathrm{eV}$ and the absence of absorption at $1.75-2.75 \mathrm{eV}$ are responsible for the green color of the material. In nano-NiO this absorption range is covered by a broad tail that is due to $\mathrm{Ni}^{3+}$ states and leads to a black appearance of the material. ${ }^{41}$ Indeed, $\mathrm{Ni}_{2} \mathrm{O}_{3}$ is black. ${ }^{43}$ Band gap $\left(E_{\mathrm{g}}\right)$ values for nano- and bulk-NiO were determined by extrapolation of the linear region of each constructed

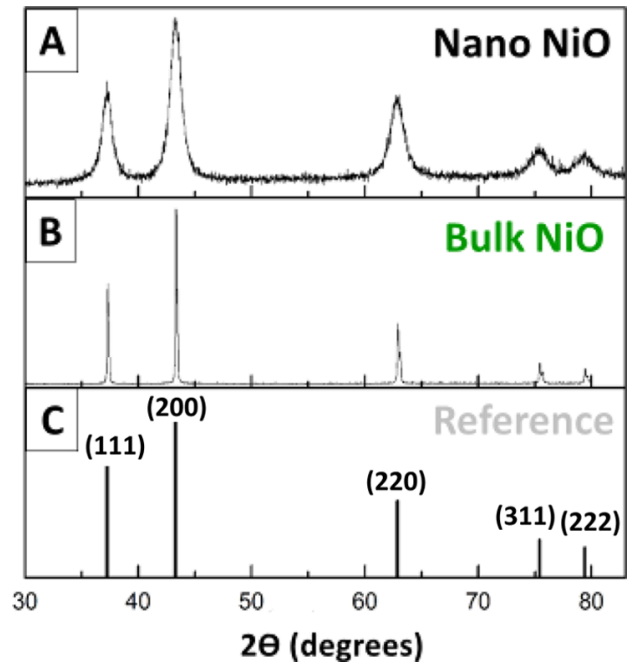

Figure 1. Powder X-ray diffraction patterns of $\mathrm{NiO}$ nanocrystals (A), bulk $\mathrm{NiO}(\mathrm{B})$, and $\mathrm{NiO}$ reference pattern (C) (JCPDS No. 71-1179).

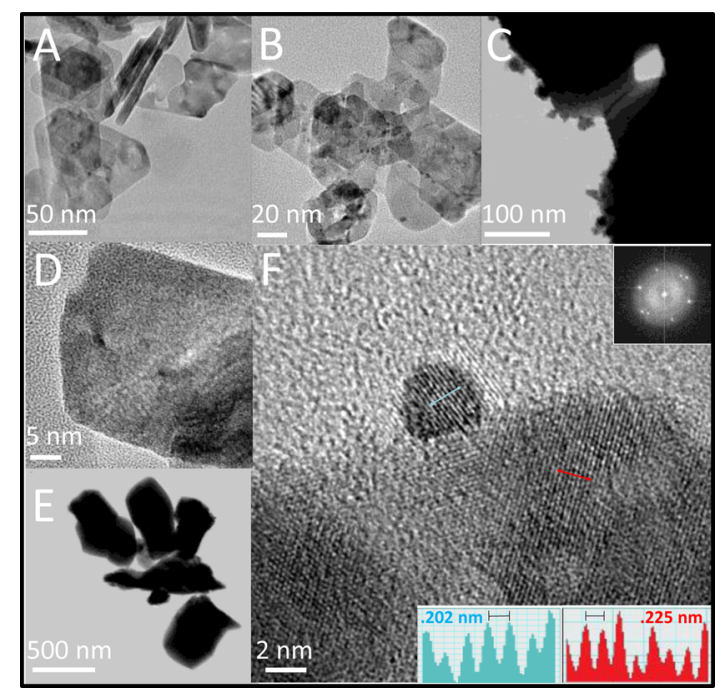

Figure 2. HRTEM images of nano NiO (A,D), Bulk NiO (E), PtNano NiO (B) and Pt-Bulk NiO (C). Lattice spacings of nano NiO along the [111] direction $(0.225 \mathrm{~nm})$ and $\mathrm{Pt}$ nano NiO along the [110] direction $(0.202 \mathrm{~nm})$ are shown in the inset of panel (F).

Tauc plot (Figure $3 \mathrm{C}, \mathrm{D}$ ). For nano-NiO this analysis yields a band gap of $3.45 \mathrm{eV}$ close to the literature value of $3.5 \mathrm{eV}$ for NiO. ${ }^{41}$ For bulk-NiO the Tauc analysis is not clear because of the additional $2.5-3.25 \mathrm{eV}$ absorption bands. As mentioned above, previous studies support a photoelectrical and photocatalytic function in $\mathrm{NiO} .{ }^{35,37-39}$ To determine if $\mathrm{NiO}$ is able to photocatalytically evolve hydrogen, $20 \mathrm{mg}$ of the $\mathrm{NiO}$ catalysts were irradiated under full spectrum from a Xe lamp in an aqueous solution of $20 \%$ methanol.

Formation of $\mathrm{H}_{2}$ was observed in all irradiation experiments, and rates were stable over $6 \mathrm{~h}$ (Figure 4). Nano-NiO is more active $\left(0.8 \mu \mathrm{mol} \mathrm{H}_{2} \mathrm{~h}^{-1}\right)$ than bulk$\mathrm{NiO}\left(0.5 \mu \mathrm{mol} \mathrm{H}_{2} \mathrm{~h}^{-1}\right)$, which may be attributed to improved carrier transport to the surface, as observed before for $\mathrm{HCa}_{2} \mathrm{Nb}_{3} \mathrm{O}_{10}{ }^{44,45}$ and $\mathrm{Fe}_{2} \mathrm{O}_{3}{ }^{46}$ 

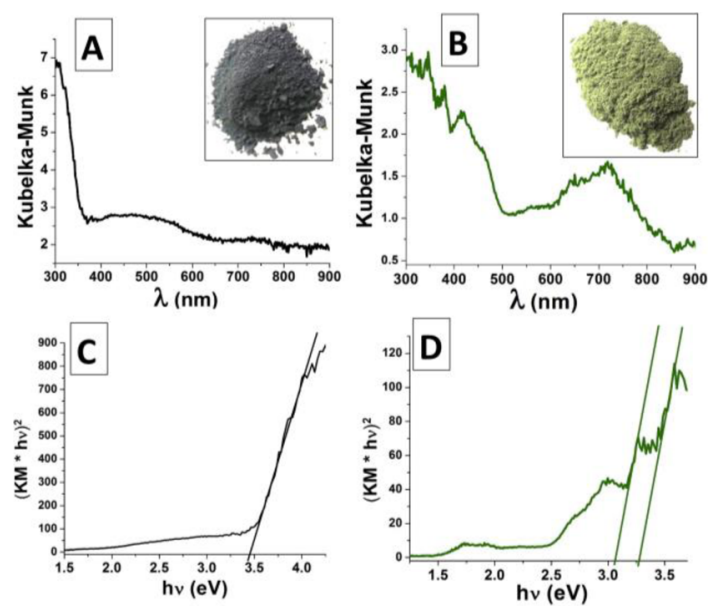

Figure 3. Diffuse reflectance spectra $(A, B)$ and direct-transition Tauc plots $(C, D)$ for nano- and bulk-NiO, respectively. Inserts: Photographs of NiO.

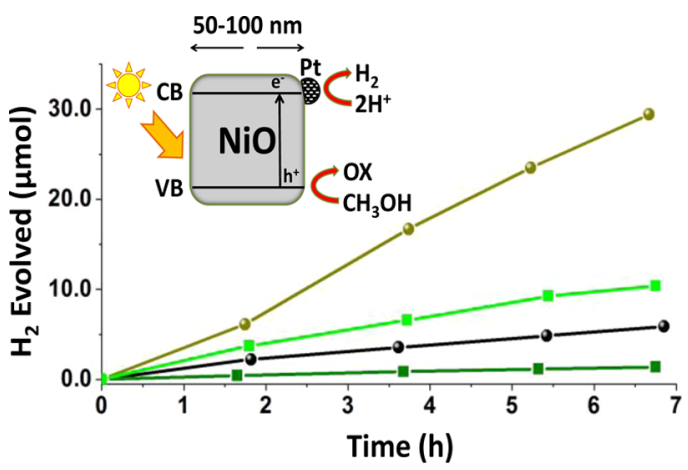

Figure 4. Hydrogen evolution from Pt nano-NiO [brown circle], Pt-bulk NiO [light green square], nano-NiO [black circle], bulk-NiO [dark green square] in $75 \mathrm{~mL}$ of $20 \%$ (vol) aqueous methanol at $\mathrm{pH}=7$ under full spectrum irradiation. Catalyst amount: $20 \mathrm{mg}$, light intensity at flask: $80 \mathrm{~mW} \mathrm{~cm}$.

An increase in hydrogen evolution occurs after photochemical platination of $\mathrm{NiO}$ with $\mathrm{H}_{2} \mathrm{PtCl}_{6}$ (see Experimental Section). Platination leads to $2-5 \mathrm{~nm} \mathrm{Pt}$ nanocrystals on the surface of nano-NiO (Figure 2BF). For bulk $\mathrm{NiO}$, the $\mathrm{Pt}$ crystals are slightly larger (10-20 nm, Figure 2C). Platinated nano-NiO evolves $4.5 \mu \mathrm{mol} \mathrm{H}_{2} \mathrm{~h}^{-1}$, which corresponds to a quantum efficiency of less than $0.1 \%$. However, turnover numbers for nano-NiO and platinated nano-NiO were 0.53 and 1.05 at $62 \mathrm{~h}$, respectively (Figure S1), supporting a catalytic function. Bulk-NiO/Pt is less active, with a rate of $2.1 \mu \mathrm{mol} \mathrm{H} \mathrm{H}^{-1}$.

In order to determine the cause for the enhanced photocatalytic activity of nano-NiO, electrochemical measurements were conducted on thin films of the materials. Figure 5 shows photoelectrochemical scans under full spectrum illumination (Xe lamp, $40 \mathrm{~mW} \mathrm{~cm}^{-2}$ ) and in the presence of methylviologen dichloride $\left(\mathrm{MVCl}_{2}\right)$ as a sacrificial electron acceptor. Both materials produce cathodic photocurrents at potentials negative of $0.0 \mathrm{~V}$ ( $v s \mathrm{NHE}$ ) that can be attributed to $\mathrm{MV}^{2+}$ reduction. The nano-NiO photoelectrode exhibited

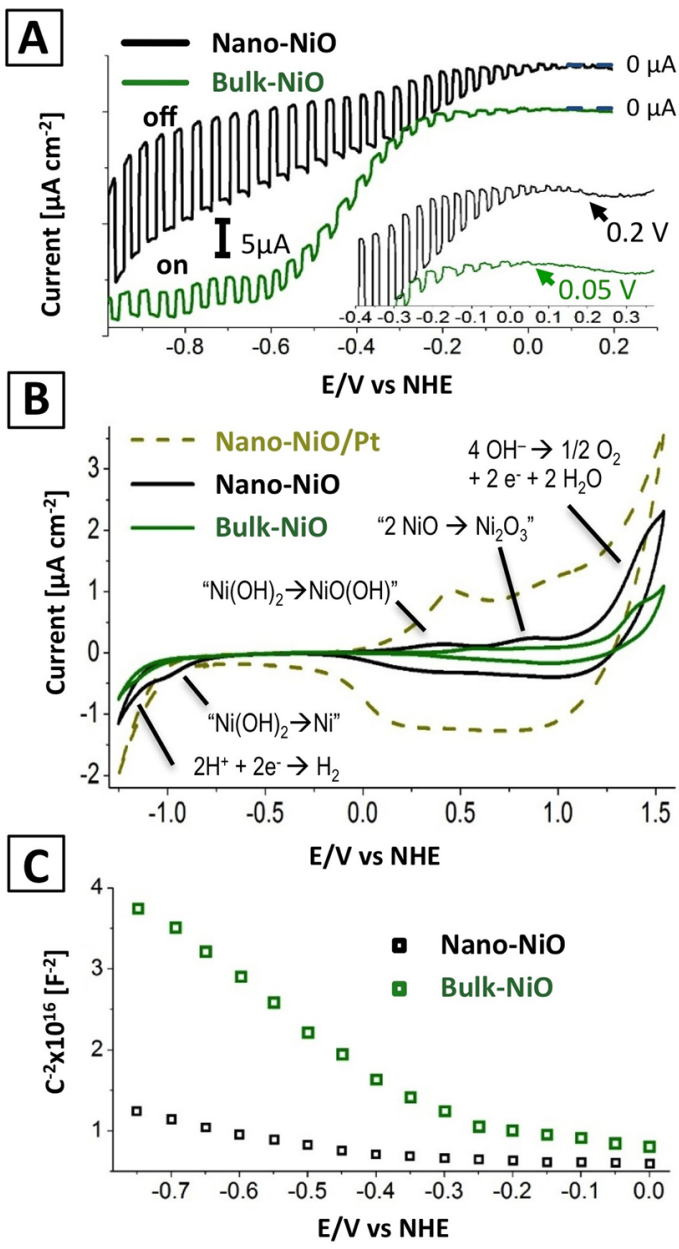

Figure 5. Chopped light photocurrent scans (A) for nano$\mathrm{NiO}$ and bulk-NiO in $0.1 \mathrm{M} \mathrm{KCl}$ at $\mathrm{pH}=7$ with $0.001 \mathrm{M} \mathrm{MVCl}_{2}$. Inset shows onset of photocurrent. Electrochemical dark scans (B) of nano-NiO, bulk-NiO, Pt:nano-NiO in $0.1 \mathrm{M} \mathrm{KCl}$ at $\mathrm{pH}=7$. (C) Mott-Schottky plots of $\mathrm{NiO}$ films in $0.1 \mathrm{M} \mathrm{KCl}$ at $\mathrm{pH}=7$.

significantly higher photocurrent $\left(5-8 \mu \mathrm{A} \mathrm{cm}^{-2}\right)$ compared to bulk $\mathrm{NiO}\left(1-3 \mu \mathrm{A} \mathrm{cm}{ }^{-2}\right)$ demonstrating its enhanced ability to transfer minority charge carriers (electrons) to $\mathrm{MV}^{2+}$. This is a direct result of the smaller particle size of nano-NiO and its increased interfacial area with the liquid phase.

To investigate the stability of the $\mathrm{NiO}$ films, electrochemical scans were conducted in $0.1 \mathrm{M} \mathrm{KCl}$ solution at $\mathrm{pH}=7$ (Figure 4B). Only small dark currents are observed for bulk-NiO, which appears stable over the entire potential range between -1.0 and $+1.3 \mathrm{~V}$. The cathodic feature at $E_{\mathrm{app}}<-1.0 \mathrm{~V}$ is due to the water reduction, as confirmed by the evolution of $\mathrm{H}_{2}$ bubbles at the working electrode. This current is increased in Pt-modified NiO films, because of the lower proton reduction overpotential of Pt. Thermodynamically, $\mathrm{H}_{2}$ is able to reduce $\mathrm{NiO}$ to nickel metal, but the reaction is slow at ambient temperature. ${ }^{47,48}$ The dark current at $+1.3 \mathrm{~V}$ can be attributed to water oxidation, based on the comparison with literature values. ${ }^{33,37,49,50}$ 
Additional cathodic and anodic redox features are observed for nano-NiO and nano-NiO/Pt that can be attributed to the reduction and oxidation of $\mathrm{Ni}^{2+}$ ion. For nano-NiO the dark currents are stronger because of the increased solid-liquid interface. Platination of $\mathrm{NiO}$ amplifies the current because the introduction of the metallic particles increases the electronic conductance of the films. The small cathodic feature at -0.9 to $-1.1 \mathrm{~V}$ for nano-NiO has been previously associated with the reduction of $\mathrm{Ni}(\mathrm{OH})_{2}$ to $\mathrm{Ni}$ metal. ${ }^{51}$

The anodic feature at $+0.3 \mathrm{~V}$ (NHE) has been attributed to the oxidation of surface $\mathrm{Ni}(\mathrm{OH})_{2}$ to $\mathrm{NiO}(\mathrm{OH}) .^{51}$ A second anodic feature follows at $E>+0.75 \mathrm{~V}$, which has been previously assigned to the oxidation of $\mathrm{NiO}$ to $\mathrm{Ni}_{2} \mathrm{O}_{3}{ }^{52}$ Finally, at $E>+1.25 \mathrm{~V}$ water oxidation to oxygen occurs. Overall, the larger surface area of nano$\mathrm{NiO}$ reduces the electrochemical stability of the material, compared to bulk-NiO. This limits its photocatalytic function to a narrow window between -0.9 and $+0.3 \mathrm{~V}$ (vs NHE). Indeed, under mild reducing bias $\left(E_{\mathrm{app}}=-0.3 \mathrm{~V}\right.$ vs $\left.\mathrm{NHE}\right)$ nano-NiO supports a relatively stable cathodic photocurrent over a period of $80 \mathrm{~min}$, as shown in Figure $\mathrm{S} 2$. For bulk-NiO the photocurrent is about half, due to the lower charge carrier density in bulk-NiO and due to the lower surface area. To further investigate the reason for the enhanced photoresponse of nano-NiO, Mott-Schottky plots for bulk and nano $\mathrm{NiO}$ films were recorded in $0.1 \mathrm{KCl}$ solution (Figure 4D). For both materials, linear plots with a negative slope confirm p-type character. On the basis of the ratio of the inverse slopes of the plots, the hole carrier density of nano-NiO is approximately four times higher than for bulk-NiO. However, because of the nanostructured morphology of the films no quantitative analysis of the doping levels and of the flatband potentials is possible. A better estimate of the Fermi energies $E_{\mathrm{F}}$ is obtained from the photocurrent onset potential of the cathodic current. In the presence of the fast electron acceptor $\mathrm{MV}^{2+}$, the photocurrent onset gives the quasi Fermi level $\left(E_{\mathrm{Fh}}\right)$ of the majority carriers in a material. ${ }^{53-55}$ The data in the inset of Figure 4A yields $E_{\mathrm{Ph}}=+0.20$ for nano-NiO and $E_{\mathrm{Ph}}=+0.05 \mathrm{~V}$ for the bulk material. These values are slightly more negative than the $+0.4 \mathrm{~V}$ flat band potential measured at $\mathrm{pH} 7$ for an amorphous $\mathrm{NiO}$ film deposited electrochemically from $\mathrm{NiSO}_{4} /$ glycine solution, ${ }^{18}$ but they compare well to the $4.6 \mathrm{eV} \mathrm{NiO}$ work function from photoemission spectra. ${ }^{56}$ The more oxidizing $E_{\mathrm{F}}$ value for nano-NiO indicates a stronger p-type character in the nanomaterial, in line with the results of the Mott-Schottky analysis. Using the Nernst equation, the $0.15 \mathrm{~V} E_{\mathrm{F}}$ difference between bulk and nano-NiO corresponds to a $\sim 350$ times higher hole concentration in nano-NiO. To verify this assessment, XPS spectra were recorded for both $\mathrm{NiO}$ particle sizes (Figure S3). The spectra reveal that one-half of the $\mathrm{Ni}$ is in the +3

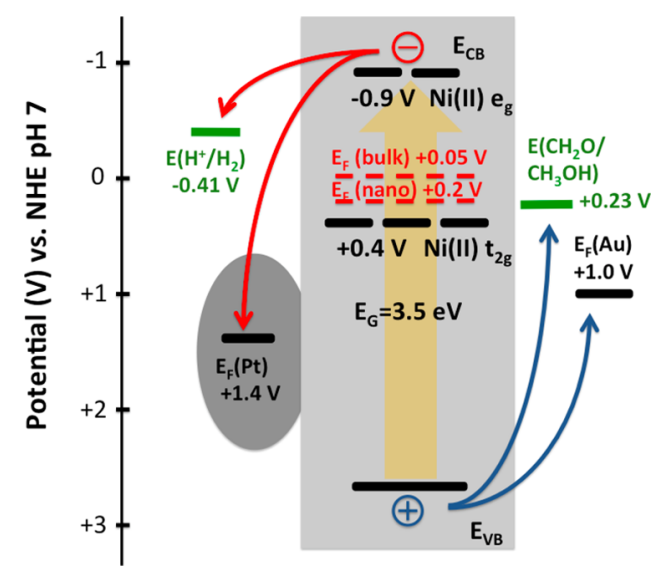

Figure 6. Energy diagram of nano-NiO on the electrochemical scale. Positions of $\mathrm{Ni}^{2+} \mathrm{e}_{\mathrm{g}}$ and $\mathrm{t}_{2 \mathrm{~g}}$ orbitals are taken from the electrochemical reduction $(-0.9 \mathrm{~V})$ and oxidation $(+0.4 \mathrm{~V})$ potentials in Figure 5B. The valence band edge is constructed from $E_{C B}$ and the optical band gap (3.5 eV). Work functions ${ }^{66}$ and the methanol oxidation potential ${ }^{67}$ are from the literature.

oxidation state and the other half in the +2 oxidation state. Interestingly, for the bulk $\mathrm{NiO}$ particles the same $\mathrm{Ni}^{3+/ 2+}$ ratio is found. This is because $10 \mathrm{keV}$ XPS beam probes only $0.37 \mathrm{~nm}$ of the particle surface layer, but not the particle core of bulk-NiO. The surface $\mathrm{Ni}^{3+}$ content in NiO has been revealed by earlier XPS studies to be a result of oxygen chemisorption. ${ }^{57-59}$ This and the electrochemical and optical studies confirm that the higher $\mathrm{Ni}^{3+}$ concentration in nano-NiO is a direct result of the smaller size of the crystals and their increased surface area, which can be estimated as 11 times that of the bulk, based on the relative particle sizes and shapes. The improved photocurrent of the nano-NiO films is due to the higher surface area and the increased majority carrier concentration. The higher carrier concentration raises the electric conductivity and reduces the Ohmic potential drop across the film. The relationship between conductivity and photocurrent is well established for many metal oxides, including $\mathrm{n}-\mathrm{WO}_{3},{ }^{60} \mathrm{n}-\mathrm{BiVO}_{4}{ }^{61,62} \mathrm{n}-\mathrm{SrTiO}_{3}{ }^{63}$ and $\mathrm{n}-\mathrm{Fe}_{2} \mathrm{O}_{3}$. ${ }^{64}$ The higher surface area and the smaller particle size reduce the minority carrier diffusion distance and enables faster electron injection into the redox couple in the liquid phase. This effect is analogous to that observed for nanoscale forms of $\mathrm{WO}_{3},{ }^{60} \mathrm{n}-\mathrm{Fe}_{2} \mathrm{O}_{3}{ }^{46}$ n-BiVO ${ }_{4}{ }^{65}$ and other inorganic light absorbers with short minority carrier diffusion length.

The electrochemical and optical data in Figures 3 and 5 can be used to construct the energy diagram in Figure 6. The scheme is consistent with the literature ${ }^{41,42}$ and reveals that the $\mathrm{NiO}$ conduction band is sufficiently negative for proton reduction at $\mathrm{pH}=7$. Bulk- and nano-NiO are similar in terms of the energetics, except for a slightly more oxidizing quasi Fermi level in the nanomaterial, as explained above. The position of the Fermi level near the conduction band 


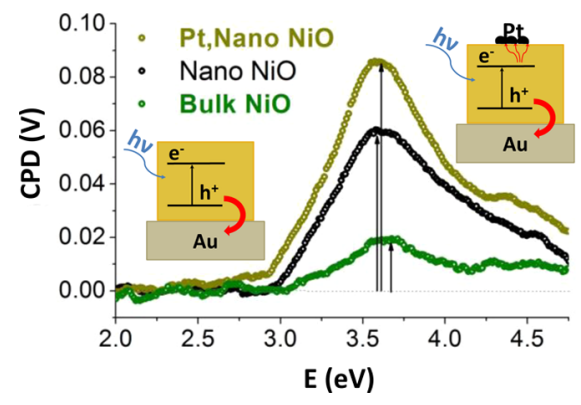

Figure 7. Surface photovoltage spectra of nano- and bulkNiO films on gold substrate in a vacuum $\left(2 \times 10^{-4} \mathrm{mbar}\right)$ and with light power density of $\sim 0.1 \mathrm{~mW} / \mathrm{cm}^{-2}$.

edge is unusual for a p-type material. It arises from the localization of some of the holes in $\mathrm{Ni}^{2+} t_{2 g}$ orbitals, near the mid of the gap.

To further analyze the kinetics of charge separation in illuminated $\mathrm{NiO}$ particles, surface photovoltage spectra (SPS) were recorded for the various samples. In SPS, a Kelvin probe measures light-induced changes in the contact potential difference (CPD) as a function of the energy of incoming photons. SPS has been previously used as an effective technique for probing photochemical charge transfer at nanostructured interfaces. ${ }^{68-73}$ Figure 7 shows SPS spectra for particle films of $\mathrm{NiO}$ on a gold substrate. For nano- and bulk$\mathrm{NiO}$ a positive photovoltage signal appears at photon energies $>3.1 \mathrm{eV}$. This energy is below the optically determined band gap of $3.5 \mathrm{eV}$, which shows that subgap states, likely at the particle surfaces, contribute to the photovoltage. The positive sign of the voltage is due to majority (hole) carrier injection into the $\mathrm{Au}$ substrate, as shown in the inset of Figure 7. This confirms p-type character for $\mathrm{NiO}$, despite the negative Fermi level in Figure 7. The photovoltage increases with photon energy to reach a maximum value at $3.6 \mathrm{eV}$, near the optical band gap, and then decreases to nearly zero due to the finite light absorption depth of the material. While bulk-NiO yields a maximum $\triangle \mathrm{CPD}$ of $19 \mathrm{mV}$, nano-NiO yields $60 \mathrm{mV}$. In light of the similar Fermi levels and band gaps of both materials, this photovoltage boost is attributed to improved electron trapping in surface states in nano-NiO.

The addition of the Pt cocatalyst raises the photovoltage maximum to $87 \mathrm{mV}$. This is due to minority carrier (electron) injection into the Pt nanoparticles (see insert). Minority carrier injection is favored by the large Pt workfunction and by the close proximity of
$\mathrm{Pt}$ and $\mathrm{NiO}$ particles which promotes transfer of shortlived carriers. The $\sim 30 \mathrm{mV}$ voltage increase can be interpreted as the $\mathrm{Pt}-\mathrm{NiO}$ junction potential. This shows that the effect of Pt on photocatalytic hydrogen evolution not only consists in reducing the proton reduction overpotential, but also in increasing the electron-hole separation in the photocatalyst. But overall, photovoltages in the Pt-NiO-Au system fall short of the values predicted by thermodynamics. According to Figure 6 , the built-in voltage of the Au-NiO contact (for hole injection) is $+1.6 \mathrm{~V}$ and that of the Pt-NiO contact (or electron injection) is $+2.3 \mathrm{~V}$. The former voltage is limited by the low hole mobility in $\mathrm{NiO}^{21}$ and the latter voltage by competitive hole injection. The low intensity of the illumination source $\left(0.1 \mathrm{~mW} \mathrm{~cm}^{-2}\right)$ plays a lesser role as we have previously obtained large photovoltages for $\mathrm{HCa}_{2} \mathrm{Nb}_{3} \mathrm{O}_{10}$ under similar illumination conditions. ${ }^{71}$

\section{CONCLUSIONS}

In conclusion, we have provided the first demonstration of suspended $\mathrm{NiO}$ particles as UV-responsive photocatalyst for $\mathrm{H}_{2}$ evolution from aqueous methanol. It was also shown that nano-NiO is catalytically and photoelectrochemically more active than bulk-NiO, because of improved minority carrier extraction across the larger surface. Importantly, nano-NiO was found to have an increased p-type character, based on electrochemical and photo-onset measurements, and based on the black color of the material. The increased p-character of nano-NiO is due to surface $\mathrm{Ni}^{3+}$ states resulting from the chemisorption of oxygen. Because the surface of nano-NiO is larger than that of bulk-NiO, its $\mathrm{Ni}^{3+}$ content is increased. This shows that nanoscaling can affect the carrier concentration in metal oxides. Furthermore, we showed that added Pt nanoparticles improve the photocatalytic activity of $\mathrm{NiO}$. This occurs not only because Pt lowers the proton reduction overpotential but also because it increases electron hole separation at the NiO-Pt interface. The small Pt-NiO junction potential of $30 \mathrm{mV}$ is due to competitive hole (majority carrier) injection. Overall, the function of $\mathrm{NiO}$ as a photocatalyst is fundamentally limited by its electrochemical instability outside of the $-0.9 \mathrm{~V}$ to $+0.3 \mathrm{~V}$ ( vs NHE) potential window, and by its large band gap that precludes sunlight absorption. These results are relevant to the understanding of $\mathrm{NiO}$-containing photocatalysts $^{33}$ and to the electronic properties of nanoscale metal oxides and junctions.

\section{EXPERIMENTAL SECTION}

Nanosize $\mathrm{NiO}$ was synthesized according to the literature ${ }^{40}$ by dissolving $0.75 \mathrm{~g}$ of $\mathrm{Ni}\left(\mathrm{NO}_{3}\right)_{2} \cdot\left(\mathrm{H}_{2} \mathrm{O}\right)_{6}$ (Acros Organics, $>99 \%$ pure) in $30 \mathrm{~mL}$ of pure water (resistivity $>18 \mathrm{M} \Omega$ ) before adjusting the solution to $\mathrm{pH} 12$ with $5 \mathrm{M} \mathrm{KOH}$ (Fisher Scientific, >99\% pure) and stirring for $1 \mathrm{~h}$ to form green solid $\mathrm{Ni}(\mathrm{OH})_{2}$. This mixture was then heated at $160^{\circ} \mathrm{C}$ in a high-pressure stainless steel autoclave for $8 \mathrm{~h}$ and washed by centrifugation in pure water and absolute ethanol separately. A light green $\mathrm{Ni}(\mathrm{OH})_{2}$ solid was obtained in $70 \%$ yield and converted to a light black $\mathrm{NiO}$ by heating at $500{ }^{\circ} \mathrm{C}$ in a tube furnace for $3 \mathrm{~h}$ in air. Bulk NiO particles (99.99\% pure) were obtained from Sigma-Aldrich CAS 1313-99-1.

Platinum was deposited onto the nano-NiO and bulk-NiO particles by irradiating the $50 \mathrm{mg}$ in a solution of $0.5 \mathrm{~mL}$ of 
$\mathrm{H}_{2} \mathrm{PtCl}_{6} \quad(1.0 \mathrm{mg} / \mathrm{mL}, \quad>99.9 \%$ pure, Sigma-Aldrich CAS $16921-30-5)$ in $100 \mathrm{~mL}$ of water (1 wt \% Pt) and $10 \%$ (vol) methanol for $2 \mathrm{~h}$ under illumination from a $300 \mathrm{~W}$ Xe arc lamp. Platinated powders were washed repeatedly in pure water then dried under a vacuum.

Powder X-ray diffraction spectroscopy was performed at standard temperatures using a Scintag XRD and a monochromatic wavelength of $\lambda=0.154 \mathrm{~nm}$ with $2 \mathrm{~mm}$ tube slit divergence. A quartz dish served as the sample holder.

High resolution transmission electron microscopy (HRTEM) images were taken using a JEOL 2500SE at $200 \mathrm{kV}$ accelerating potential. Transmission electron microscopy (TEM) images were taken using a Philips CM12 at $120 \mathrm{kV}$. Samples were prepared by submerging carbon-coated $\mathrm{Cu}$ grids in aqueous suspensions of $\mathrm{NiO}$ particles followed by rinsing with water and drying at room temperature.

UV-vis diffuse reflectance spectra were recorded on solid films using a Thermo Scientific Evolution 220 Spectrometer equipped with an integrating sphere. The reflectance data were converted with the Kubelka-Munk function $\left[f(R)=(1-R)^{2} /(2 R)\right]$ to correct for light loss due to scattering.

The rates of photochemical $\mathrm{H}_{2}$ evolution were determined by irradiating $20 \mathrm{mg}$ of $\mathrm{NiO}$ catalyst dispersed in a $20 \%$ (vol) aqueous methanol solution and analyzing the gas evolved using a gas chromatograph (Varian 3800). Irradiations were performed in a quartz flask using a $300 \mathrm{~W}$ Xe arc lamp with a measured power output of $500 \mathrm{~mW} \mathrm{~cm}^{-2}(\lambda=280-660 \mathrm{~nm})$ at the flask. Output in ultraviolet region $(\lambda=260-350 \mathrm{~nm})$ was approximately $80 \mathrm{~mW} \mathrm{~cm} \mathrm{~cm}^{-2}$. For long-duration $\mathrm{H}_{2}$ evolution experiments (S1) an increased light intensity was used $\left(150 \mathrm{~mW} \mathrm{~cm}^{-2}, \lambda=260-350 \mathrm{~nm}\right)$ along with a higher concentration of sacrificial reagent $(\mathrm{MeOH})$.

For electrochemical measurements, $\mathrm{NiO}$ electrodes were prepared by drop casting $\mathrm{NiO}$ powders on $\mathrm{F}: \mathrm{SnO}_{2}$ (FTO) substrates and annealing at $350{ }^{\circ} \mathrm{C}$ for $1 \mathrm{~h}$. The NiO working electrode was connected in a 3-electrode configuration with a Pt counter electrode and a saturated calomel reference electrode (SCE). Aqueous electrolyte solution (0.1 $\left.\mathrm{M} \mathrm{K}_{2} \mathrm{SO}_{4}, \mathrm{pH} 7\right)$ was added to the cell and bubbled with $\mathrm{N}_{2}$ gas to remove all dissolved oxygen prior to scanning. Methyl viologen dichloride hydrate ( $98 \%$ pure, Sigma-Aldrich CAS 75365-73-0) was used in photocurrent onset scans (Xe lamp, $40 \mathrm{~mW} \mathrm{~cm}^{-2}$ ) to ensure fast reaction kinetics at the electrode surface. Electrochemical impedance/capacitance measurements were performed in $0.1 \mathrm{M} \mathrm{KCl}(\mathrm{pH} 7)$ at a frequency of $4 \times 10^{4} \mathrm{~Hz}$. The cell was calibrated with the redox potential of $\mathrm{K}_{4}\left[\mathrm{Fe}(\mathrm{CN})_{6}\right]$ at $+0.358 \mathrm{~V}$ vs NHE.

Surface photovoltage spectroscopy (SPS) measurements were performed with a vibrating gold Kelvin probe (Delta PHI Besocke) mounted inside a vacuum chamber equipped with quartz window. Data were collected while films were illuminated under a vacuum $\left(2 \times 10^{-4} \mathrm{mBar}\right)$ with monochromatic light. The CPD spectra were corrected for drift effects by subtracting dark scan data.

Conflict of Interest: The authors declare no competing financial interest.

Acknowledgment. We are grateful for financial support from Research Corporation for Science Advancement (Scialog Award) and from the National Science Foundation (NSF, Grants 1152250 and 1133099).

Supporting Information Available: Photocurrent scans, longterm irradiation and XPS data. This material is available free of charge via the Internet at http://pubs.acs.org.

\section{REFERENCES AND NOTES}

1. Lewis, N. S.; Nocera, D. G. Powering the Planet: Chemical Challenges in Solar Energy Utilization. Proc. Natl. Acad. Sci. U. S. A. 2006, 103, 15729-15735.

2. DOE Basic Research Needs for Solar Energy Utilization; Department of Energy: Washington, D.C., 2005.

3. DOE Basic Research Needs: Catalysis for Energy; Department of Energy: Washington, D.C., 2007.

4. Osterloh, F. E. Inorganic Nanostructures for Photoelectrochemical and Photocatalytic Water Splitting. Chem. Soc. Rev. 2013, 42, 2294-2320.
5. Osterloh, F. E. Inorganic Materials as Catalysts for Photochemical Splitting of Water. Chem. Mater. 2008, 20, 35-54.

6. Kudo, A.; Miseki, Y. Heterogeneous Photocatalyst Materials for Water Splitting. Chem. Soc. Rev. 2009, 38, 253-278.

7. Abe, R.; Sayama, K.; Domen, K.; Arakawa, H. A New Type of Water Splitting System Composed of Two Different $\mathrm{TiO}_{2}$ Photocatalysts (Anatase, Rutile) and a $\mathrm{IO}_{3}{ }^{-} / \mathrm{I}^{-}$Shuttle Redox Mediator. Chem. Phys. Lett. 2001, 344, 339-344.

8. Kudo, A. Z-Scheme Photocatalyst Systems for Water Splitting under Visible Light Irradiation. MRS Bull. 2011, 36, 32-38.

9. Abe, R. Recent Progress on Photocatalytic and Photoelectrochemical Water Splitting under Visible Light Irradiation. J. Photochem. Photobiol., C 2010, 11, 179-209.

10. Maeda, K.; Higashi, M.; Lu, D. L.; Abe, R.; Domen, K. Efficient Nonsacrificial Water Splitting Through Two-Step Photoexcitation by Visible Light Using a Modified Oxynitride as a Hydrogen Evolution Photocatalyst. J. Am. Chem. Soc. 2010, 132, 5858-5868.

11. Katayama, M.; Yokoyama, D.; Maeda, Y.; Ozaki, Y.; Tabata, M.; Matsumoto, Y.; Ishikawa, A.; Kubota, J.; Domen, K. Fabrication and Photoelectrochemical Properties of $\mathrm{La}_{5} \mathrm{Ti}_{2} \mathrm{MS}_{5} \mathrm{O}_{7}(\mathrm{M}=\mathrm{Ag}, \mathrm{Cu})$ Electrodes. Mater. Sci. Eng., $B$ 2010, 173, 275-278.

12. Iwashina, K.; Kudo, A. Rh-Doped $\mathrm{SrTiO}_{3}$ Photocatalyst Electrode Showing Cathodic Photocurrent for Water Splitting under Visible-Light Irradiation. J. Am. Chem. Soc. 2011, 133, 13272-13275.

13. Joshi, U. A.; Palasyuk, A. M.; Maggard, P. A. Photoelectrochemical Investigation and Electronic Structure of a p-Type $\mathrm{CuNbO}_{3}$ Photocathode. J. Phys. Chem. C 2011, 115, 13534-13539.

14. Joshi, U. A.; Maggard, P. A. $\mathrm{CuNb}_{3} \mathrm{O}_{8}$ : A p-Type Semiconducting Metal Oxide Photoelectrode. J. Phys. Chem. Lett. 2012, 3, 1577-1581.

15. Maeda, K. Rhodium-Doped Barium Titanate Perovskite as a Stable p-Type Semiconductor Photocatalyst for Hydrogen Evolution under Visible Light. ACS Appl. Mater. Interfaces 2014, 6, 2167-2173.

16. Paracchino, A.; Laporte, V.; Sivula, K.; Graetzel, M.; Thimsen, E. Highly Active Oxide Photocathode for Photoelectrochemical Water Reduction. Nat. Mater. 2011, 10, 456-461.

17. Hu, C.; Chu, K.; Zhao, Y.; Teoh, W. Y. Efficient Photoelectrochemical Water Splitting over Anodized p-Type NiO Porous Films. ACS Appl. Mater. Interfaces 2014, 6, 1855818568.

18. Nakaoka, K.; Ueyama, J.; Ogura, K. Semiconductor and Electrochromic Properties of Electrochemically Deposited Nickel Oxide Films. J. Electroanal. Chem. 2004, 571, 93-99.

19. Natu, G.; Hasin, P.; Huang, Z. J.; Ji, Z. Q.; He, M. F.; Wu, Y. Y. Valence Band-Edge Engineering of Nickel Oxide Nanoparticles via Cobalt Doping for Application in p-Type DyeSensitized Solar Cells. ACS Appl. Mater. Interfaces 2012, 4, 5922-5929.

20. Nattestad, A.; Mozer, A. J.; Fischer, M. K. R.; Cheng, Y. B.; Mishra, A.; Bauerle, P.; Bach, U. Highly Efficient Photocathodes for Dye-Sensitized Tandem Solar Cells. Nat. Mater. 2010, 9, 31-35.

21. Odobel, F.; Pellegrin, Y. Recent Advances in the Sensitization of Wide-Band-Gap Nanostructured p-Type Semiconductors. Photovoltaic and Photocatalytic Applications. J. Phys. Chem. Lett. 2013, 4, 2551-2564.

22. Habas, S. E.; Platt, H. A. S.; van Hest, M.; Ginley, D. S. LowCost Inorganic Solar Cells: From Ink to Printed Device. Chem. Rev. 2010, 110, 6571-6594.

23. Kudo, A.; Sayama, K.; Tanaka, A.; Asakura, K.; Domen, K.; Maruya, K.; Onishi, T. Nickel-Loaded $\mathrm{K}_{4} \mathrm{Nb}_{6} \mathrm{O}_{17}$ Photocatalyst in the Decomposition of $\mathrm{H}_{2} \mathrm{O}$ into $\mathrm{H}_{2}$ and $\mathrm{O}_{2}$ : Structure and Reaction Mechanism. J. Catal. 1989, 120, 337-352.

24. Sayama, K.; Tanaka, A.; Domen, K.; Maruya, K.; Onishi, T. Photocatalytic Decomposition of Water over a Ni-Loaded $\mathrm{Rb}_{4} \mathrm{Nb}_{6} \mathrm{O}_{17}$ Catalyst. J. Catal. 1990, 124, 541-547.

25. Takata, T.; Furumi, Y.; Shinohara, K.; Tanaka, A.; Hara, M.; Kondo, J. N.; Domen, K. Photocatalytic Decomposition of Water on Spontaneously Hydrated Layered Perovskites. Chem. Mater. 1997, 9, 1063-1064. 
26. Ikeda, S.; Hara, M.; Kondo, J. N.; Domen, K.; Takahashi, $\mathrm{H}$.; Okubo, T.; Kakihana, M. Preparation of $\mathrm{K}_{2} \mathrm{La}_{2} \mathrm{Ti}_{3} \mathrm{O}_{10}$ by Polymerized Complex Method and Photocatalytic Decomposition of Water. Chem. Mater. 1998, 10, 72-77.

27. Kato, H.; Asakura, K.; Kudo, A. Highly Efficient Water Splitting into $\mathrm{H}_{2}$ and $\mathrm{O}_{2}$ over Lanthanum-Doped $\mathrm{NaTaO}_{3}$ Photocatalysts with High Crystallinity and Surface Nanostructure. J. Am. Chem. Soc. 2003, 125, 3082-3089.

28. Baba, R.; Fujishima, A. Where is the Actual Site for Hydrogen Evolution-Isotopic Analysis for NiO-Deposited $\mathrm{SrTiO}_{3}$ Photocatalyst. J. Electroanal. Chem. 1986, 213, 319-321.

29. Domen, K.; Naito, S.; Soma, M.; Onishi, T.; Tamaru, K. Photocatalytic Decomposition of Water-Vapor on an NiO-SrTiO 3 Catalyst. J. Chem. Soc., Chem. Commun. 1980, 543-544.

30. Domen, K.; Naito, S.; Onishi, T.; Tamaru, K. Study of the Photocatalytic Decomposition of Water-Vapor over a NiO-SrTiO ${ }_{3}$ Catalyst. J. Phys. Chem. 1982, 86, 3657-3661.

31. Niishiro, R.; Kato, H.; Kudo, A. Nickel and Either Tantalum or Niobium-Codoped $\mathrm{TiO}_{2}$ and $\mathrm{SrTiO}_{3}$ Photocatalysts with Visible-Light Response for $\mathrm{H}_{2}$ or $\mathrm{O}_{2}$ Evolution from Aqueous Solutions. Phys. Chem. Chem. Phys. 2005, 7, 2241-2245.

32. Hu, C.-C.; Teng, H. Structural Features of P-Type Semiconducting $\mathrm{NiO}$ as a Co-Catalyst for Photocatalytic Water Splitting. J. Catal. 2010, 272, 1-8.

33. Townsend, T. K.; Browning, N. D.; Osterloh, F. E. Overall Photocatalytic Water Splitting with $\mathrm{NiOx}-\mathrm{SrTiO}_{3}-\mathrm{A}$ Revised Mechanism. Energy Environ. Sci. 2012, 5, 9543-9550.

34. Xie, S.; Zhai, T.; Zhu, Y.; Li, W.; Qiu, R.; Tong, Y.; Lu, X. NiO Decorated $\mathrm{Mo}: \mathrm{BiVO}_{4}$ Photoanode with Enhanced VisibleLight Photoelectrochemical Activity. Int. J. Hydrogen Energy 2014, 39, 4820-4827.

35. Domen, K.; Kudo, A.; Onishi, T. Mechanism of Photocatalytic Decomposition of Water into $\mathrm{H}_{2}$ and $\mathrm{O}_{2}$ over NiO$\mathrm{SrTiO}_{3}$. J. Catal. 1986, 102, 92-98.

36. Zhang, Z.; Shao, C.; Li, X.; Wang, C.; Zhang, M.; Liu, Y. Electrospun Nanofibers of p-Type NiO/n-Type ZnO Heterojunctions with Enhanced Photocatalytic Activity. ACS Appl. Mater. Interfaces 2010, 2, 2915-2923.

37. Dare-Edwards, M. P.; Goodenough, J. B.; Hamnett, A.; Nicholson, N. D. Photoelectrochemistry of Nickel(II) Oxide. J. Chem. Soc., Faraday Trans. 2 1981, 77, 643-661.

38. Wan, X.; Yuan, M.; Tie, S.-I.; Lan, S. Effects of Catalyst Characters on the Photocatalytic Activity and Process of $\mathrm{NiO}$ Nanoparticles in the Degradation of Methylene Blue. Appl. Surf. Sci. 2013, 277, 40-46.

39. Duan, H.; Zheng, X.; Yuan, S.; Li, Y.; Tian, Z.; Deng, Z.; Su, B. Sub-3 nm NiO Nanoparticles: Controlled Synthesis, and Photocatalytic Activity. Mater. Lett. 2012, 81, 245-247.

40. Zhang, X.; Shi, W.; Zhu, J.; Zhao, W.; Ma, J.; Mhaisalkar, S.; Maria, T.; Yang, Y.; Zhang, H.; Hng, H.; Yan, Q. Synthesis of Porous NiO Nanocrystals with Controllable Surface Area and Their Application as Supercapacitor Electrodes. Nano Res. 2010, 3, 643-652.

41. Newman, R.; Chrenko, R. M. Optical Properties of Nickel Oxide. Phys. Rev. 1959, 114, 1507-1513.

42. Fujimori, A.; Minami, F. Valence-Band Photoemission and Optical-Absorption in Nickel Compounds. Phys. Rev. B: Condens. Matter Mater. Phys. 1984, 30, 957-971.

43. Davidson, A.; Tempere, J. F.; Che, M.; Roulet, H.; Dufour, G. Spectroscopic Studies of Nickel(II) and Nickel(III) Species Generated upon Thermal Treatments of Nickel CeriaSupported Materials. J. Phys. Chem. 1996, 100, 4919-4929.

44. Sabio, E. M.; Chamousis, R. L.; Browning, N. D.; Osterloh, F. E. Correction: Photocatalytic Water Splitting with Suspended Calcium Niobium Oxides: Why Nanoscale is Better than Bulk_A Kinetic Analysis. J. Phys. Chem. C 2012, 116, 1905119051.

45. Sabio, E. M.; Chamousis, R. L.; Browning, N. D.; Osterloh, F. E. Photocatalytic Water Splitting with Suspended Calcium Niobium Oxides: Why Nanoscale is Better than Bulk_A Kinetic Analysis. J. Phys. Chem. C 2012, 116, 31613170 .

46. Townsend, T. K.; Sabio, E. M.; Browning, N. D.; Osterloh, F. E. Photocatalytic Water Oxidation with Suspended alpha- $\mathrm{Fe}_{2} \mathrm{O}_{3}$ Particles - Effects of Nanoscaling. Energy Environ. Sci. 2011, 4, 4270-4275.

47. Parravano, G. The Reduction of Nickel Oxide by Hydrogen. J. Am. Chem. Soc. 1952, 74, 1194-1198.

48. Rodriguez, J. A.; Hanson, J. C.; Frenkel, A. I.; Kim, J. Y.; Perez, M. Experimental and Theoretical Studies on the Reaction of $\mathrm{H}_{2}$ with NiO: Role of $\mathrm{O}$ Vacancies and Mechanism for Oxide Reduction. J. Am. Chem. Soc. 2002, 124, 346-354.

49. Trasatti, S. Electrocatalysis by Oxides-Attempt at a Unifying Approach. J. Electroanal. Chem. 1980, 111, 125-131.

50. McCrory, C. C. L.; Jung, S. H.; Peters, J. C.; Jaramillo, T. F. Benchmarking Heterogeneous Electrocatalysts for the Oxygen Evolution Reaction. J. Am. Chem. Soc. 2013, 135, 16977-16987.

51. Vukovic, M. Voltammetry and Anodic Stability of a Hydrous Oxide Film on a Nickel Electrode in Alkaline-Solution. J. Appl. Electrochem. 1994, 24, 878-882.

52. Yohe, D.; Riga, A.; Greef, R.; Yeager, E. Electrochemical Properties of Nickel Oxide. Electrochim. Acta 1968, 13, 1351.

53. Zhao, J.; Holmes, M. A.; Osterloh, F. E. Quantum Confinement Controls Photocatalysis-A Free Energy Analysis for Photocatalytic Proton Reduction at CdSe Nanocrystals. ACS Nano 2013, 7, 4316-4325.

54. Chamousis, R. L.; Osterloh, F. E. Use of Potential Determining lons to Control Energetics and Photochemical Charge Transfer of a Nanoscale Water Splitting Photocatalyst. Energy Environ. Sci. 2014, 7, 736-743.

55. Butler, M. A. Photoelectrolysis and Physical Properties of Semiconducting Electrode $\mathrm{WO}_{3}$. J. Appl. Phys. 1977, 48, 1914-1920.

56. Yang, C. J.; Park, J. I.; Cho, Y. R. Enhanced Field-Emission Obtained from NiO Coated Carbon Nanotubes. Adv. Eng. Mater. 2007, 9, 88-91.

57. Tyuliev, G.; Sokolova, M. Temperature-Dependence of $\mathrm{Ni}^{3+}$ Quantity in the Surface-Layer of NiO. Appl. Surf. Sci. 1991, 52, 343-349.

58. Brundle, C. R.; Carley, A. F. Oxygen Adsorption on Nickel Surfaces: Detection of Different Species by X-Ray Photoelectron Spectroscopy. Chem. Phys. Lett. 1975, 31, 423-427.

59. Roberts, M. W.; Smart, R. S. C. Evidence From Photoelectron Spectroscopy for Dissociative Adsorption of Oxygen on Nickel Oxide. Surf. Sci. 1981, 108, 271-280.

60. Zhao, J.; Olide, E.; Osterloh, F. E. Enhancing Majority Carrier Transport in $\mathrm{WO}_{3}$ Water Oxidation Photoanode via Electrochemical Doping. J. Electrochem. Soc. 2015, 162, H65-H71.

61. Abdi, F. F.; Firet, N.; van de Krol, R. Efficient BiVO 4 Thin Film Photoanodes Modified with Cobalt Phosphate Catalyst and W-doping. Chem CatChem 2013, 5, 490-496.

62. Seabold, J. A.; Zhu, K.; Neale, N. R. Efficient Solar Photoelectrolysis by Nanoporous $\mathrm{Mo:} \mathrm{BiVO}_{4}$ Through Ccontrolled Electron Transport. Phys. Chem. Chem. Phys. 2014, 16, 1121-1131.

63. Kumar, A.; Santangelo, P. G.; Lewis, N. S. Electrolysis of Water at $\mathrm{SrTiO}_{3}$ Photoelectrodes_Distinguishing Between the Statistical and Stochastic Formalisms for Electron-Transfer Processes in Fuel-Forming Photoelectrochemical Systems. J. Phys. Chem. 1992, 96, 834-842.

64. Liang, Y. Q.; Enache, C. S.; van de Krol, R. Photoelectrochemical Characterization of Sprayed Alpha- $\mathrm{Fe}_{2} \mathrm{O}_{3}$ Thin Films: Influence of Si Doping and $\mathrm{SnO}_{2}$ Interfacial Layer. Int. J. Photoenergy 2008, 10.1155/2008/739864.

65. Berglund, S. P.; Flaherty, D. W.; Hahn, N. T.; Bard, A. J.; Mullins, C. B. Photoelectrochemical Oxidation of Water Using Nanostructured BiVO 4 Films. J. Phys. Chem. C 2011, 115, 3794-3802.

66. Lide, D. R. Electron Work Function of the Elements. In CRC Handbook of Chemistry and Physics; CRC Press/Taylor and Francis: Boca Raton, FL, 2008; Vol. 88 (Internet Version 2008).

67. Burstein, G. T.; Barnett, C. J.; Kucernak, A. R.; Williams, K. R. Aspects of the Anodic Oxidation of Methanol. Catal. Today 1997, 38, 425-437.

68. Lagowski, J. Semiconductor Surface Spectroscopies-The Early Years. Surf. Sci. 1994, 299, 92-101. 
69. Kronik, L.; Shapira, Y. Surface Photovoltage Phenomena: Theory, Experiment, and Applications. Surf. Sci. Rep. 1999, 37, 1-206.

70. Kronik, L.; Shapira, Y. Surface Photovoltage Spectroscopy of Semiconductor Structures: At the Crossroads of Physics, Chemistry and Electrical Engineering. Surf. Interface Anal. 2001, 31, 954-965.

71. Zhao, J.; Osterloh, F. E. Photochemical Charge Separation in Nanocrystal Photocatalyst Films - Insights from Surface Photovoltage Spectroscopy. J. Phys. Chem. Lett. 2014, 5, 782-786.

72. Osterloh, F. E.; Holmes, M. A.; Zhao, J.; Chang, L.; Kawula, S.; Roehling, J. D.; Moulé, A. J. P3HT:PCBM Bulk-Heterojunctions: Observing Interfacial and Charge Transfer States with Surface Photovoltage Spectroscopy. J. Phys. Chem. C 2014, 118, 14723-14731.

73. Osterloh, F. E.; Holmes, M. A.; Chang, L.; Moule, A. J.; Zhao, J. Photochemical Charge Separation in Poly(3-hexylthiophene) (P3HT) Films Observed with Surface Photovoltage Spectroscopy. J. Phys. Chem. C 2013, 117, 26905-26913. 